\title{
Three water sites in upper mantle olivine and the role of titanium in the water weakening mechanism
}

\author{
A. M. Walker, ${ }^{1,3}$ J. Hermann, ${ }^{1}$ A. J. Berry, ${ }^{2}$ and H. St. C. O’Neill ${ }^{1}$ \\ Received 11 July 2006; revised 6 January 2007; accepted 21 February 2007; published 25 May 2007.
}

[1] Infrared spectroscopy on synthetic olivines has established that there are at least four different mechanisms by which hydrogen is incorporated into the crystal structure. Two mechanisms occur in the system $\mathrm{MgO}-\mathrm{SiO}_{2}-\mathrm{H}_{2} \mathrm{O}$ associated with silicon and magnesium vacancies, respectively. A third mechanism is associated with trivalent cation substitution, commonly $\mathrm{Fe}^{3+}$ in natural olivine, while the fourth mechanism, which is the one most prevalent in natural olivines from the spinel-peridotite facies of the Earth's upper mantle, is associated with $\mathrm{Ti}^{4+}$ [Berry et al., 2005]. Here first principles calculations based on density functional theory are used to derive the structure and relative energies of the two defects in the pure $\mathrm{MgO}-\mathrm{SiO}_{2}-\mathrm{H}_{2} \mathrm{O}$ system, and possible hydrogen-bearing and hydrogen-free point defects in $\mathrm{Ti}^{4+}$-doped forsterite. Calculated structures are used to compare the predicted orientation of the $\mathrm{O}-\mathrm{H}$ bonds with the experimentally determined polarization. The energies are used to discuss how different regimes of chemical environment, temperature $(T)$, pressure $(P)$, and both water content and water fugacity $\left(f_{\mathrm{H}_{2} \mathrm{O}}\right)$, impact on which of the different hydroxyl substitution mechanisms are thermodynamically stable. We find that given the presence of Ti impurities, the most stable mechanism involves the formation of silicon vacancies containing two protons charge balanced by a $\mathrm{Ti}^{4+}$ cation occupying an adjacent octahedral site. This mechanism leads to the water-mediated formation of silicon vacancies. As silicon is known to be the most slowly diffusing species in olivine, this provides a credible explanation of the observed water weakening effect in olivine.

Citation: Walker, A. M., J. Hermann, A. J. Berry, and H. St. C. O’Neill (2007), Three water sites in upper mantle olivine and the role of titanium in the water weakening mechanism, J. Geophys. Res., 112, B05211, doi:10.1029/2006JB004620.

\section{Introduction}

[2] The great effect of small amounts of hydrogen on the physical properties of the nominally anhydrous minerals (NAMs) that make up Earth's upper mantle is well known and has been the subject of extensive study. The substitution of hydrogen in silicate minerals occurs by bonding to lattice oxygen to form hydroxyl groups $\left(\mathrm{OH}^{-}\right)$, and such hydroxyl is colloquially known in the petrologic literature as "water." In olivine, the important effects of hydrogen include a major decrease in strength in both the dislocation and diffusional creep regime [Mei and Kohlstedt, 2000a, 2000b], an increase in electrical conductivity [Karato, 1990; Wang et al., 2006; Yoshino et al., 2006], and a postulated increase in the attenuation of seismic energy [Karato and Jung, 1998]. These changes have important implications for understanding the behavior of our planet. For example, a plausible

\footnotetext{
${ }^{1}$ Research School of Earth Sciences, The Australian National University, Canberra, Australia.

${ }^{2}$ Department of Earth Science and Engineering, Imperial College London, London, UK.

${ }^{3}$ Now at Department of Earth Sciences, University of Cambridge, Cambridge, UK.
}

Copyright 2007 by the American Geophysical Union. 0148-0227/07/2006JB004620\$09.00 explanation for the dramatic difference in the global tectonic processes occurring on Venus and Earth [Solomon et al., $1991]$ is the presence of low concentrations of water dissolved in the terrestrial mantle, decreasing the upper mantle viscosity on Earth when compared to Venus [Kaula, 1990, 1995] and permitting the development of subduction zones on Earth [Regenauer-Lieb et al., 2001; Regenauer-Lieb and $K o h l, 2003]$. It is also possible that diffusing hydrogen ions are the main charge carriers in the mantle, dominating the observed electromagnetic response. For example, Lizarralde et al. [1995] and Evans et al. [1999] suggest that hydrogen diffusion through olivine is active under the Pacific, while a recent analysis suggests that this could be the main mechanism of electrical conductivity active in the anisotropic subcontinental upper mantle in a study area under northern Europe [Gatzemeier and Moorkamp, 2005].

[3] In order to understand how dissolved water so drastically affects physical properties, it is first necessary to determine the mechanisms leading to its incorporation in NAMs. A powerful tool to probe the local structure around the $\mathrm{OH}^{-}$groups in NAMs is infrared (IR) spectroscopy. For pure synthetic forsterite in the simple system $\mathrm{MgO}-\mathrm{SiO}_{2}-$ $\mathrm{H}_{2} \mathrm{O}$, experiments where the silica activity was varied yield distinct IR fingerprints that clearly distinguish when forsterite is buffered by $\mathrm{MgO}$ (IR absorbance peaks close to 3612,3579 , and $3567 \mathrm{~cm}^{-1}$; see Figure 1) from when 


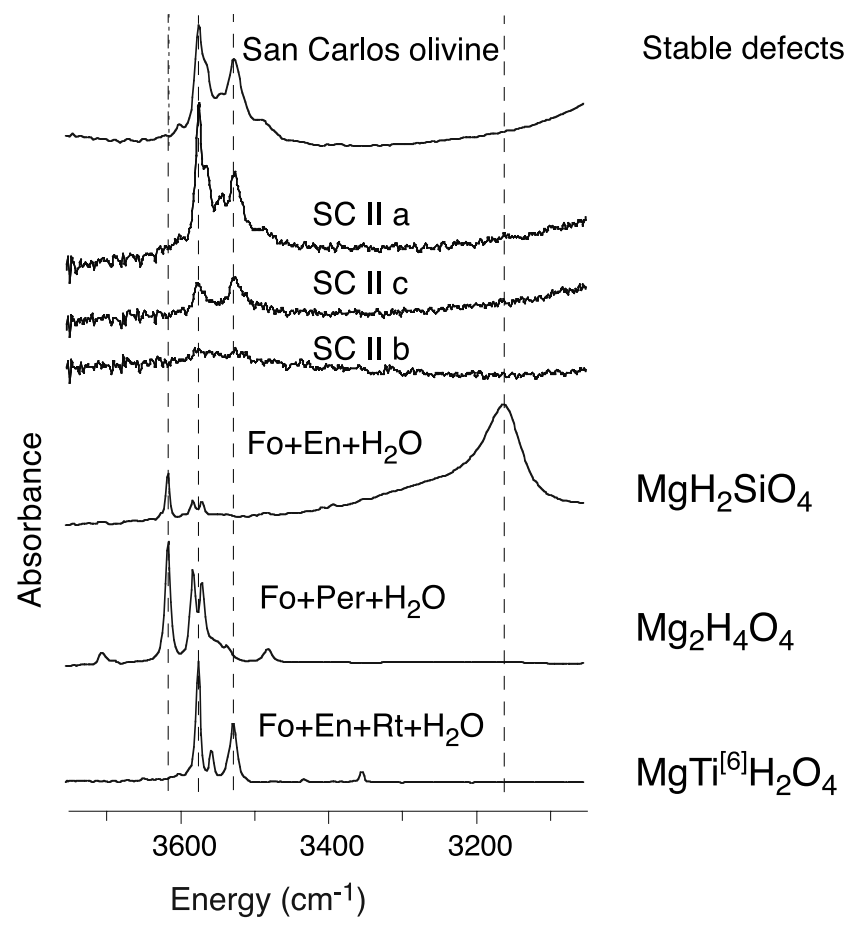

Figure 1. Unpolarized and polarized infrared spectra of San Carlos olivine and unpolarized olivine spectra from experimental runs. The proposed stable hydrous defects are indicated for the experimental olivine spectra ( $\mathrm{Fo}=$ forsterite, $\mathrm{Rt}=$ rutile, $\mathrm{Per}=$ periclase, $\mathrm{En}=$ enstatite) .

forsterite is buffered by pyroxene (broad peaks at 3160 and $3220 \mathrm{~cm}^{-1}$ ). The interpretation of this result is that hydrated silicon vacancies (i.e., a vacant silicon site with each of the four oxygen atoms surrounding the vacancy bonded to hydrogen atoms) form when the system is MgO-buffered and hydrated magnesium vacancies (a magnesium vacancy with two of the surrounding oxygen atoms bonded to hydrogen atoms) form in the pyroxene-buffered case [Matveev et al., 2001; Lemaire et al., 2004]. This interpretation posed a problem for the understanding of the spectra of natural mantle-derived samples, as their most common IR fingerprint from the spinel-peridotite facies (peaks close to 3572 and $3525 \mathrm{~cm}^{-1}$ ) is more similar to that found in the MgO-buffered experiments, despite the presence of pyroxene in the Earth's upper mantle [Matveev et al., 2001]. The explanation for this seeming paradox is that the spectra of the natural olivines are actually due to a third type of substitution, in which the $\mathrm{OH}^{-}$group is associated with Ti, a trace element substituting in natural olivines [Berry et al., 2005]. This titanium fingerprint is present whether the sample is buffered by $\mathrm{MgO}$ or pyroxene and is similar to the group I peaks of Bai and Kohlstedt [1993]. To complicate matters still further, a fourth type of defect associated with trivalent cation impurities has been identified (Berry et al., in preparation), which produces peaks in the IR spectra at 3355 and $3325 \mathrm{~cm}^{-1}$ in Fe-bearing olivines associated with $\mathrm{Fe}^{3+}$, perhaps produced by late-stage oxidation [Berry et al., 2005]. In addition to these common fingerprints, exotic samples collected from atypical localities can host much more hydrogen and display many more peaks in the IR spectra. For example, Koch-Müller et al. [2006] and
Matsyuk and Langer [2004] described suites of "wet" xenocrysts from kimberlite pipes and other mantle-derived olivines and identified 23 and 70 IR peaks, respectively. We do not consider these complex and unusual spectra here and concentrate on the simple spectra observed from experiment and typically "dry" olivine samples, such as those from olivine xenocrysts from San Carlos, AZ, studied by Berry et al. [2005] and reported in Figure 1.

[4] The recognition that hydrogen is incorporated in olivine by several different mechanisms raises the question of which mechanisms are stable under which conditions. To investigate this, we have undertaken first principles calculations based on density functional theory to derive the structure and relative energies of the two defects in the pure $\mathrm{MgO}-\mathrm{SiO}_{2}$ system, and possible hydrogen-bearing and hydrogen-free point defects in $\mathrm{Ti}^{4+}$-doped forsterite. The temperature and pressure dependence of these three defect types is also calculated, allowing a quantitative assessment of their relative stabilities as a function of these variables as well as chemical environment including water content and fugacity $\left(f_{\mathrm{H}_{2} \mathrm{O}}\right)$.

\section{Methodology}

[5] First principles calculations aim to simulate the behavior of matter at the atomic scale without relying on experimental information, apart from some fundamental physical constants. The key step is to calculate the ground state energy of a system consisting of electrons in an external potential field describing the interactions between the electrons and atomic nuclei; this requires the solution of the (time-independent) Schrödinger equation. For condensed matter, the dominant approach is to transform the Schrödinger equation into a form where the energy of the system is written as a functional of the electron density. This procedure leads to a mathematically exact expression for the energy and avoids the need for the calculation of the many body wave function. The cost of this procedure is the need to introduce an approximate exchange-correlation functional (the existence of an exact exchange-correlation functional can be proven; however, its form is both complex and unknown). With the ability to calculate the energy of any arrangement of nuclei, one can move nuclei around in order to find energy minima which correspond to stable or metastable structures. In the present application, these structures correspond to defects in forsterite crystals. The model of the defects makes use of periodic boundary conditions to remove boundary effects, and a three-stage process is used in order to identify the role of titanium on the incorporation of water in forsterite. The mechanism of titanium incorporation in hydrogen-free forsterite is examined by calculating the energies and structures of various simulation cells containing titanium(IV) and other chargecompensating defects, if they are required. The incorporation mechanism of hydrogen in titanium-free forsterite is examined by calculating the energies and structures of cells with cation vacancies surrounded by charge-compensating hydrogen ions, which are bonded to the oxygen atoms around the vacant polyhedra. Finally, possible reactions between the point defects that form during the process of titanium and hydrogen incorporation are considered by calculating the structure and energies of cells containing 
composite defects and comparing the energies with the unbound but charge neutral alternatives.

[6] In order to calculate the energies of the various possible hydrogen and titanium incorporation mechanisms, and to establish the structure of the resulting defects, we modeled a wide range of point defects in forsterite. The point defects studied were all charge neutral and included those that may form as a result of titanium incorporation in dry forsterite, silicon, and magnesium vacancies surrounded by hydroxyl groups and various possible defect clusters containing both titanium and hydrogen associated with cation vacancies. Each of the defects was embedded in a $2 \times 1 \times 2$ forsterite supercell. This gives a unit cell in which the smallest dimension is approximately $9.6 \AA$, sufficiently large to minimize undesirable defect-defect interactions, allowing the energies to be considered as those for a dilute population of defects [Richmond and Brodholt, 2000].

[7] Density functional theory [Hohenberg and Kohn, 1964; Kohn and Sham, 1965] as implemented using the SIESTA methodology [Soler et al., 2002] was used to calculate the energies and find the minimum energy configuration of all the simulation cells. Calculations were performed within the generalized gradient approximation using the exchange-correlation functional of Perdew et al. [1996]. The SIESTA methodology makes use of a numerical basis of a linear combination of pseudoatomic orbitals to describe the valence electrons, and pseudopotentials to describe the core electrons and nuclei. This approach allows the large number of possible defect configurations to be studied without unfeasible computational requirements. For all atom types, the valence orbitals were described using a double-zeta polarized basis consisting of atomic orbitals that were confined within a smooth potential that becomes asymptotic to infinity at a chosen radius [Junquera et al., 2001]. Within the SIESTA methodology, an auxiliary basis set is employed to compute the exchange-correlation and Hartree energies, consisting of a uniform real space grid. A kinetic energy cutoff of 250 Ry and $2 \times 2 \times 2$ grid cell sampling were used in order to yield sufficient numerical convergence.

[8] In addition to performing calculations on the perfect and defective olivine systems, the optimized structures and energies of magnesium oxide and enstatite were also determined in order to compute the total energy change of a number of relevant defect reactions. For the calculations on the bulk phases, Monkhorst-Pack mesh sizes of $6 \times 6 \times 6$ and $2 \times 3 \times 5$ were utilized for $\mathrm{MgO}$ and enstatite, respectively. In the case of the olivine $2 \times 1 \times 2$ supercell, reciprocal space was sampled only at the gamma point. While this leads to total energies that are not absolutely converged, the error in the energy differences is found to be less than $0.01 \mathrm{eV}$ and therefore not significant with respect to thermal energy or the inherent uncertainties underlying density functional theory (Ordejón et al. [2001] and Martin [2004] give overviews of the accuracy of SIESTA and density functional theory, respectively).

[9] The locations of the nuclei in each simulation box are moved in order to minimize the calculated energy of the system. Minimization is performed using the method of conjugate gradients, and convergence is assumed once the total force on each atom has become smaller than $0.01 \mathrm{eV}$
$\AA^{-1}$. For the simulation cells containing defects, in order to simulate a dilute population of defects, the cell parameters are held fixed at the values calculated for an equivalent defectfree cell. Cell parameters of these perfect model crystals were varied as part of the energy minimization, and convergence was assumed when all components of the calculated stress tensor became smaller than $0.02 \mathrm{GPa}$. For calculations at high pressure, we applied an isotropic external stress to the model crystal and optimized the structure while allowing the cell parameters to vary. For defective forsterite, the resulting smaller cell was used as the basis of the defective supercells, which were optimized with fixed cell parameters.

\section{Results}

\subsection{The Mg-Vacancy and Si-Vacancy Mechanisms}

[10] The first task is to identify the mechanisms of water incorporation in titanium-free forsterite in the system $\mathrm{MgO}$ $\mathrm{SiO}_{2}-\mathrm{H}_{2} \mathrm{O}$, i.e., with no impurity species. Experimental work [Matveev et al., 2001; Lemaire et al., 2004] has shown that two mechanisms are observed, at low and high activity of silica, when the forsterite coexists with periclase $(\mathrm{MgO})$ or enstatite $\left(\mathrm{MgSiO}_{3}\right)$, respectively. The first mechanism may be represented by the equilibrium:

$$
2 \mathrm{H}_{2} \mathrm{O}+2 \mathrm{MgO} \rightarrow \mathrm{Mg}_{2} \mathrm{H}_{4} \mathrm{O}_{4}
$$

The hydrous component on the right-hand side of the equation could have a point-defect structure similar to the hydrogrossular crystal structure, i.e., a cluster of four hydroxyl groups around a silicon vacancy (Figure $2 a$ ). However, other point defects with the same stoichiometry are conceptually possible, for example, $\mathrm{Mg}$ occupying the silicon site with four protons associated with the vacated magnesium site. Furthermore, if local charge balance is not maintained, a huge variety of point-defect structures are conceptually possible, but such mechanisms seem unlikely and will not be pursued here.

[11] The second mechanism may be represented by the equilibrium:

$$
\mathrm{H}_{2} \mathrm{O}+\mathrm{MgSiO}_{3} \rightarrow \mathrm{MgH}_{2} \mathrm{SiO}_{4}
$$

Here the hydrous component represents forsterite with $\mathrm{Mg}$ vacancies bound to two hydroxyl groups. Again, this is not the only possible configuration with this stoichiometry, but other possibilities require $\mathrm{Si}$ to occupy a magnesium site and these have not been examined. We assume that the doubly protonated M1 vacancy with hydrogen bonded to the two $\mathrm{O} 2$ sites (Figure 2b) is the most stable hydrous configuration on the right-hand side [Wright and Catlow, 1994; Brodholt and Refson, 2000; Braithwaite et al., 2003].

[12] In order to explore the relative stability of these two defect configurations, without the complication of involving the energy of $\mathrm{H}_{2} \mathrm{O}$ as a component, the energetics of the reactions:

$$
\begin{aligned}
& 4 \mathrm{MgSiO}_{3}+\mathrm{Mg}_{2} \mathrm{H}_{4} \mathrm{O}_{4} \cdot 15 \mathrm{Mg}_{2} \mathrm{SiO}_{4}+ \\
& \text { enstatite olivine } \\
& 16 \mathrm{Mg}_{2} \mathrm{SiO}_{4} \rightarrow \\
& \text { olivine } \\
& \underset{\text { olivine }}{3 \mathrm{Mg}_{2} \mathrm{SiO}_{4}}+2\left(\mathrm{MgH}_{2} \mathrm{SiO}_{4} \cdot 15 \mathrm{Mg}_{2} \mathrm{SiO}_{4}\right),
\end{aligned}
$$



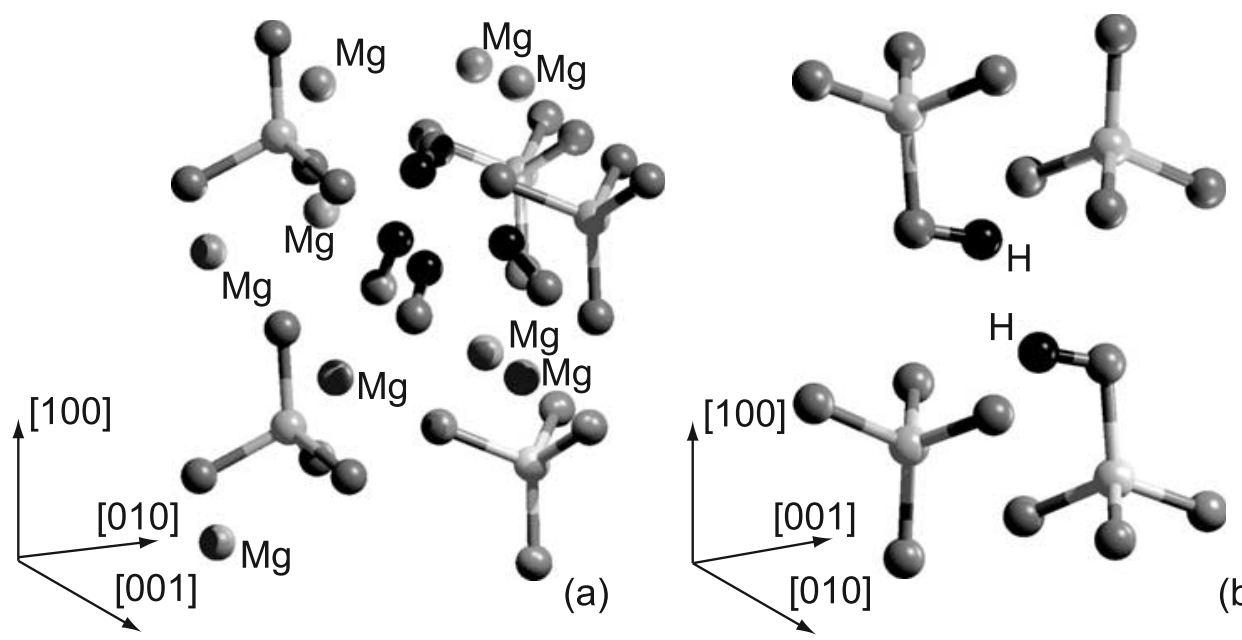

Figure 2. Structure of stable hydrated cation vacancies derived from DFT calculations. (a) Fully hydrated silicon vacancy; three of the $\mathrm{OH}$ dipoles are aligned subparallel to the [100] direction and the fourth is subparallel to the [001] direction. (b) Hydrated M1 vacancy with hydrogen bonded to two O2 oxygen atoms; both $\mathrm{OH}$ dipoles are subparallel to the [001] direction with small resolved components in the [010] direction. Hydrogen atoms in black and silicon atoms in light gray are shown bonded to oxygen atoms (in Figure 2a, four isolated $\mathrm{OH}$ groups are at the corners of a vacant Si tetrahedra). Isolated atoms in Figure $2 \mathrm{a}$ are magnesium atoms; these are omitted from Figure $2 \mathrm{~b}$.

and

$$
\begin{aligned}
& 17 \mathrm{Mg}_{2} \mathrm{SiO}_{4}+\mathrm{Mg}_{2} \mathrm{H}_{4} \mathrm{O}_{4} \cdot 15 \mathrm{Mg}_{2} \mathrm{SiO}_{4} \rightarrow \\
& \text { olivine olivine } \\
& 4 \mathrm{MgO}+2\left(\mathrm{MgH}_{2} \mathrm{SiO}_{4} \cdot 15 \mathrm{Mg}_{2} \mathrm{SiO}_{4}\right) \text {, } \\
& \text { periclase olivine }
\end{aligned}
$$

were calculated for olivine in equilibrium with enstatite and $\mathrm{MgO}$, respectively. These defect reactions can also be described using Kröger-Vink notation where vacancies are represented by a "V", and the sites are represented by subscripts with reaction (3) described by:

$$
(4 \mathrm{H})_{\mathrm{Si}}^{\times}+2 \mathrm{Mg}_{\mathrm{Mg}}^{\times}+4 \mathrm{MgSiO}_{3} \rightarrow 2(2 \mathrm{H})_{\mathrm{Mg}}^{\times}+\mathrm{Si}_{\mathrm{Si}}^{\times}+3 \mathrm{Mg}_{2} \mathrm{SiO}_{4},
$$

and reaction (4) described by:

$$
(4 \mathrm{H})_{\mathrm{Si}}^{\times}+2 \mathrm{Mg}_{\mathrm{Mg}}^{\times}+\mathrm{Mg}_{2} \mathrm{SiO}_{4} \rightarrow 2(2 \mathrm{H})_{\mathrm{Mg}}^{\times}+\mathrm{Si}_{\mathrm{Si}}^{\times}+4 \mathrm{MgO}
$$

[13] The energies for the two reactions are calculated using the total energies of the simulation cells presented in Table 1, which are designed to give the appropriate energy for isolated hydrous defects. Any residual defect-defect interactions will result in a lower dilution of the hydrous olivine component up to a maximum mole fraction of $1 / 16$ $(0.0625)$ for both hydrous components. The true dilution in the model system therefore lies between this value and the infinitely dilute isolated case. The calculation thus includes not only the energy of formation of the end-member defect but also its heat of dilution in $\mathrm{Mg}_{2} \mathrm{SiO}_{4}$ olivine. We assumed local charge balance; that is, the hydrated cation vacancies are more stable than vacancies charge balanced by more distant hydroxyl groups, which is supported by previous calculations [Wright and Catlow, 1994; Brodholt and Refson, 2000; Braithwaite et al., 2003; Walker et al., 2006], and which is also consistent with the observation that the IR frequencies change with presumed vacancy type [Matveev et al., 2001, 2005; Lemaire et al., 2004; Berry et al., 2005]. The energy changes are found to be 0.63 and $2.35 \mathrm{eV}$ per defect, corresponding to 60 and $226 \mathrm{~kJ} \mathrm{~mol}^{-1}$ for reactions (3) and (4), respectively. Pressure has only a small effect on the enthalpy of reaction (3); at $12 \mathrm{GPa}$, the equivalent reaction energy is found to be $58 \mathrm{~kJ} \mathrm{~mol}^{-1}$. Pressure has a slightly larger effect on reaction (4) with the reaction energy changing to $242 \mathrm{~kJ} \mathrm{~mol}^{-1}$.

[14] In both cases, the reaction energies favor the formation of the hydrated silicon vacancy, a situation that does not accord with the experimental finding from IR spectroscopy that the type of defect varies with the coexisting phase. The explanation lies with the configurational entropy of the two types of defects. For the $\mathrm{MgH}_{4} \mathrm{O}_{4}$ component (the $\mathrm{Si}$ vacancy with the hydrogrossular-like structure), four hydroxyl groups are associated with the Si vacancy, and the configurational entropy is given by:

$$
\begin{aligned}
& S_{\text {config }}=k_{\mathrm{B}} \ln \Omega \\
& =k_{\mathrm{B}}\left(\frac{\left(N_{\mathrm{Mg}_{2} \mathrm{SiO}_{4}}+N_{\mathrm{Mg}_{2} \mathrm{H}_{4} \mathrm{O}_{4}}\right) !}{N_{\mathrm{Mg}_{2} \mathrm{SiO}_{4} !} ! N_{\mathrm{Mg}_{2} \mathrm{H}_{4} \mathrm{O}_{4}} !}\right) \\
& =-R\left[X_{\mathrm{Mg}_{2} \mathrm{SiO}_{4}} \ln X_{\mathrm{Mg}_{2} \mathrm{SiO}_{4}}+X_{\mathrm{Mg}_{2} \mathrm{H}_{4} \mathrm{O}_{4}} \ln X_{\mathrm{Mg}_{2} \mathrm{H}_{4} \mathrm{O}_{4}}\right] \text {, }
\end{aligned}
$$

Table 1. Low-Energy Simulation Cells Used in This Study

\begin{tabular}{lcc}
\hline & \multicolumn{2}{c}{ Calculated Formation Energy, eV } \\
\cline { 2 - 3 } \multicolumn{1}{c}{ Simulation Cell } & $0 \mathrm{GPa}$ & $12 \mathrm{GPa}$ \\
\hline $\mathrm{Mg}_{2} \mathrm{SiO}_{4}$ & -3905.55 & -3905.33 \\
$\mathrm{MgSiO}$ & -2444.02 & -2443.86 \\
$\mathrm{MgO}$ & -1461.10 & -1460.99 \\
$\mathrm{Mg}_{2} \mathrm{Ti}^{[4]} \mathrm{O}_{4} \cdot 15 \mathrm{Mg}_{2} \mathrm{SiO}_{4}$ & $-63,967.17$ & $-63,962.82$ \\
$\mathrm{Ti}^{[6]} \mathrm{SiO}_{4} \cdot 15 \mathrm{Mg}_{2} \mathrm{SiO}_{4}$ & $-62,026.56$ & $-62,022.84$ \\
$\mathrm{MgTi}^{[6]} \mathrm{Mg}^{[4]} \mathrm{O}_{4} \cdot 15 \mathrm{Mg}_{2} \mathrm{SiO}_{4}$ & $-63,965.49$ & $-63,961.14$ \\
$\mathrm{MgH}_{2} \mathrm{SiO}_{4} \cdot 15 \mathrm{Mg}_{2} \mathrm{SiO}_{4}$ & $-61,494.75$ & $-61,490.94$ \\
$\mathrm{Mg}_{2} \mathrm{H}_{4} \mathrm{O}_{4} \cdot 15 \mathrm{Mg}_{2} \mathrm{SiO}_{4}$ & $-62,441.90$ & $-62,437.75$ \\
$\mathrm{MgH}_{2} \mathrm{Ti}^{[4]} \mathrm{O}_{4} \cdot 15 \mathrm{Mg}_{2} \mathrm{SiO}_{4}$ & $-63,973.28$ & $-62,969.10$ \\
$\mathrm{MgTi}^{[6]} \mathrm{H}_{2} \mathrm{O}_{4} \cdot 15 \mathrm{Mg}_{2} \mathrm{SiO}_{4}$ & $-62,974.63$ & $-62,970.74$ \\
\hline
\end{tabular}




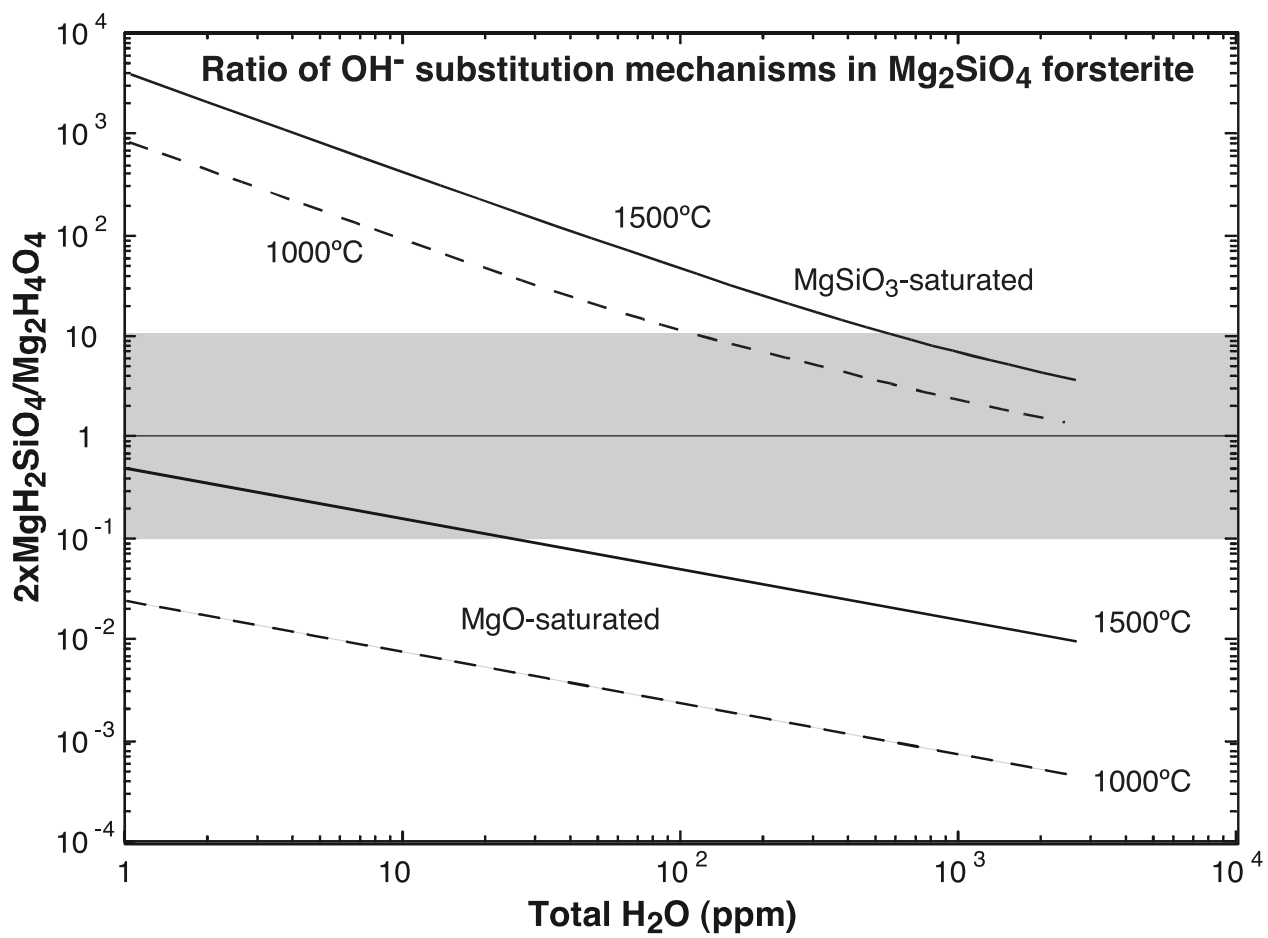

Figure 3. Ratio of $\mathrm{H}_{2} \mathrm{O}$ substituting in $\mathrm{MgH}_{2} \mathrm{SiO}_{4}$ defects (Mg vacancies) to that substituting in $\mathrm{Mg}_{2} \mathrm{H}_{4} \mathrm{O}_{4}$ defects ( $\mathrm{Si}$ vacancies) as a function of total $\mathrm{H}_{2} \mathrm{O}$ [i.e., $X_{\mathrm{MgH}_{2} \mathrm{SiO}_{4}}+0.5 X_{\mathrm{Mg}_{2} \mathrm{H}_{4} \mathrm{O}_{4}}$, but expressed as parts per million (ppm) $\mathrm{H}_{2} \mathrm{O}$ ]. The ratios are calculated at two temperatures, $1000^{\circ} \mathrm{C}$ and $1500^{\circ} \mathrm{C}$, for high $a_{\mathrm{SiO}_{2}}\left[\mathrm{MgSiO}_{3}\right.$-saturated, reaction (3)] and low $a_{\mathrm{SiO}_{2}}$ [reaction (4)].

where $k_{\mathrm{B}}$ is the Boltzmann constant, $R$ is the gas constant, $N_{\mathrm{Mg}_{2} \mathrm{SiO}_{4}}$ and $N_{\mathrm{Mg}_{2} \mathrm{H}_{4} \mathrm{O}_{4}}$ are the number of forsterite and hydrous-defect formula units in the crystal, $X_{\mathrm{Mg}_{2} \mathrm{SiO}_{4}}$ and $X_{\mathrm{Mg}_{2} \mathrm{H}_{4} \mathrm{O}_{4}}$ are the mole fraction of formula units of the two components, and $\Omega$ is the configurational permutability. Note that this expression is for the integral molar configurational entropy; the partial molar configurational entropy $\bar{S}_{\text {config }}$ of the $\mathrm{Mg}_{2} \mathrm{H}_{4} \mathrm{O}_{4}$ defect is:

$$
\bar{S}_{\text {config }}=-R \ln X_{\mathrm{Mg}_{2} \mathrm{H}_{4} \mathrm{O}_{4}} .
$$

Similarly, for the $\mathrm{MgH}_{2} \mathrm{SiO}_{4}$ component (the $\mathrm{Mg}$-vacancy defect), we have assumed the two protons to be completely associated with the $\mathrm{Mg}$ vacancy, giving an integral molar configurational entropy:

$$
S_{\text {config }}=-R\left[X_{\mathrm{Mg}_{2} \mathrm{SiO}_{4}} \ln X_{\mathrm{M}_{2} \mathrm{~S}_{2} \mathrm{Si}_{4}}+X_{\mathrm{MgH}_{2} \mathrm{SiO}_{4}} \ln X_{\mathrm{MgH}_{2} \mathrm{SiO}_{4}}\right] \text {, }
$$

and a partial molar configurational entropy:

$$
\bar{S}_{\text {config }}=-R \ln X_{\mathrm{MgH}_{2} \mathrm{SiO}_{4}} \text {. }
$$

The condition of equilibrium for a balanced chemical reaction is that the sum of the chemical potentials at constant composition is zero:

$$
\sum \nu_{i} \mu_{i}=0
$$

If we invoke the approximation that the calculated molar energy of the reaction is constant (i.e., the change in heat capacity across the reaction is zero at all temperatures; this implies, among other things, that the change in nonconfigurational or vibrational entropy across the reaction is also zero), then we have:

$$
\sum \nu_{i} \mu_{i} \cong \Delta E-T \sum \nu_{i} \bar{S}_{i, \text { onfig }} .
$$

Applying this condition to either reaction (3) or (4), we obtain, for low concentrations of defects (i.e., $X_{\mathrm{Mg}_{2} \mathrm{SiO}_{4}} \approx 1$ ):

$$
R T \ln \frac{\left(X_{\mathrm{Mg}_{2} \mathrm{SiO}_{4}}\right)^{2}}{X_{\mathrm{Mg}_{2} \mathrm{H}_{4} \mathrm{O}_{4}}}=-\Delta E .
$$

This relation may be used to calculate the ratio of $\mathrm{H}_{2} \mathrm{O}$ held by the two types of defects; the important point is that this ratio is not a constant at a given $T$ and $P$, but depends on the total amount of $\mathrm{H}_{2} \mathrm{O}$ dissolved in the olivine. The calculated ratio of water dissolved as $\mathrm{MgH}_{2} \mathrm{SiO}_{4}$ to that dissolved as $\mathrm{Mg}_{2} \mathrm{H}_{4} \mathrm{O}_{4}$, i.e., $\frac{2 X_{\mathrm{MgH}_{2} \mathrm{SiO}_{4}}}{X_{\mathrm{Mg}_{2} \mathrm{H}_{4} \mathrm{O}_{4}}}$, is plotted as a function of $\mathrm{H}_{2} \mathrm{O}$ content (calculated in ppm $\mathrm{H}_{2} \mathrm{O}$, for convenience) in Figure 3, for two temperatures $\left(1000^{\circ} \mathrm{C}\right.$ and $\left.1500^{\circ} \mathrm{C}\right)$ at the two activities of silica represented by reactions (3) (high $a_{\mathrm{SiO}_{2}}$, in equilibrium with enstatite) and reaction (4) (low $a_{\mathrm{SiO}_{2}}$, in equilibrium with periclase), respectively. The results show that when configurational entropy is taken into account, the $\mathrm{Mg}$-vacancy mechanism (the $\mathrm{MgH}_{2} \mathrm{SiO}_{4}$ component) is correctly predicted to be the more stable at high $a_{\mathrm{SiO}_{2}}$.

[15] This mechanism with its higher configurational entropy is of course also relatively stabilized by increasing temperature, but at constant temperature, the low entropy mechanism (that involving $\mathrm{Mg}_{2} \mathrm{H}_{4} \mathrm{O}_{4}$ component) becomes 
Table 2. Defect Energies for all Titanium Defects in Dry Forsterite

\begin{tabular}{|c|c|}
\hline Defect & Energy, eV \\
\hline 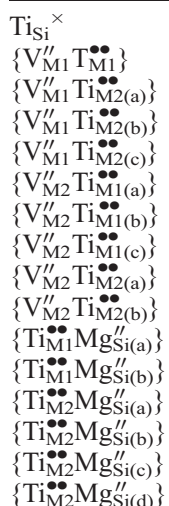 & $\begin{array}{l}-63,967.17 \\
-62,026.20 \\
-62,026.56 \\
-62,026.21 \\
-62,026.22 \\
-62,024.55 \\
-62,024.58 \\
-62,024.91 \\
-62,024.86 \\
-62,024.89 \\
-63,965.49 \\
-63,963.97 \\
-63,964.68 \\
-63,964.73 \\
-63,964.20 \\
-63,965.32\end{array}$ \\
\hline
\end{tabular}

increasingly more important with increasing total $\mathrm{H}_{2} \mathrm{O}$. High total $\mathrm{H}_{2} \mathrm{O}$ in olivine requires high $f_{\mathrm{H}_{2} \mathrm{O}}$, which is achieved in experiments by the presence of an $\mathrm{H}_{2} \mathrm{O}$-rich vapor phase at high pressure. Such conditions are not usually possible in the chemically complex Earth's mantle (high $f_{\mathrm{H}_{2} \mathrm{O}}$ would induce extensive melting); hence we emphasize that the results of simple-system experiments on $\mathrm{H}_{2} \mathrm{O}$ solubility in olivine conducted at saturation with $\mathrm{H}_{2} \mathrm{O}$ vapor at high pressures cannot be applied directly to mantle olivine, although of course such data are needed to calibrate a thermodynamic model that takes into account the different mechanism of $\mathrm{H}_{2} \mathrm{O}$ substitution.

[16] Our analysis correctly predicts that at intermediate $f_{\mathrm{H}_{2} \mathrm{O}}$ (corresponding approximately to total $\mathrm{H}_{2} \mathrm{O}$ in olivine $<$ $10^{2} \mathrm{ppm}$ ), either one mechanism or the other predominates according to whether $a_{\mathrm{SiO}_{2}}$ is buffered by $\mathrm{MgO}$ or $\mathrm{MgSiO}_{3}$, in agreement with the experimental results of Matveev et al. [2001] and Lemaire et al. [2004]. But at higher $f_{\mathrm{H}_{2} \mathrm{O}}$ and greater $\mathrm{H}_{2} \mathrm{O}$ solubilities, such as those achieved in the experiments of Kohlstedt et al. [1996], the low $a_{\mathrm{SiO}_{2}}$ mechanism should become increasingly important even when the olivine is buffered by
$\mathrm{MgSiO}_{3}$, again in agreement with the experimental observations [see Kohlstedt et al., 1996, Figure 4].

\subsection{Titanium Incorporation in Anhydrous Forsterite}

[17] The Fourier transform infrared spectra of typical olivines from the spinel-peridotite facies of the Earth's upper mantle are dominated not by either of these two defect mechanisms found in the system $\mathrm{MgO}-\mathrm{SiO}_{2}-\mathrm{H}_{2} \mathrm{O}$ but by a defect mechanism in which the $\mathrm{OH}^{-}$substitution is associated with Ti [Berry et al., 2005]. In order to understand this mechanism, it is first necessary to discuss how Ti is incorporated in $\mathrm{Mg}_{2} \mathrm{SiO}_{4}$ olivine without $\mathrm{H}_{2} \mathrm{O}$.

[18] Three distinct types of mechanism have been considered: (1) direct substitution for silicon, (2) substitution for magnesium charge balanced by a vacancy on an adjacent magnesium site, and (3) substitution for magnesium charge balanced by a magnesium ion substitution onto an adjacent silicon site. Taking two polyhedra that share at least one vertex oxygen atom as adjacent, there is one symmetrydistinct arrangement for mechanism (1), nine distinct arrangements for mechanism (2), and six distinct arrangements for mechanism (3). The calculated energies of 112 and 111 atom simulation cells at $0 \mathrm{GPa}$ containing these defect arrangements are listed in Table 2. When there is more than one arrangement of two adjacent defects (for example, a vacancy on the M1 site with titanium on an M2 site; see Figure 4), the symmetry-distinct arrangements are labeled with a lowercase letter.

[19] The content of the simulation cell is different for mechanisms (1) and (3) from mechanism (2). Comparing the energies of cells within each grouping reveals that titanium enters olivine via either direct substitution of silicon forming the $\mathrm{Ti}_{\mathrm{Si}}^{\times}$defect [the lowest energy configuration from mechanisms (1) and (3)], or via the coupled substitution $\left\{\mathrm{V}_{\mathrm{M} 1} \mathrm{Ti}_{\mathrm{M} 2 \mathrm{a}}\right\}^{\times}$[the lowest energy configuration from mechanism (2)]. As a forsterite crystal containing the $\mathrm{Ti}_{\mathrm{Si}}^{\times}$defect and any amount of titanium will have different bulk chemistry to a crystal containing the $\left\{\mathrm{V}_{\mathrm{M} 1} \mathrm{Ti}_{\mathrm{M} 2 \mathrm{a}}\right\}^{\times}$ defect and the same amount of titanium [for case $(2)$, the magnesium concentration will vary with titanium concen-
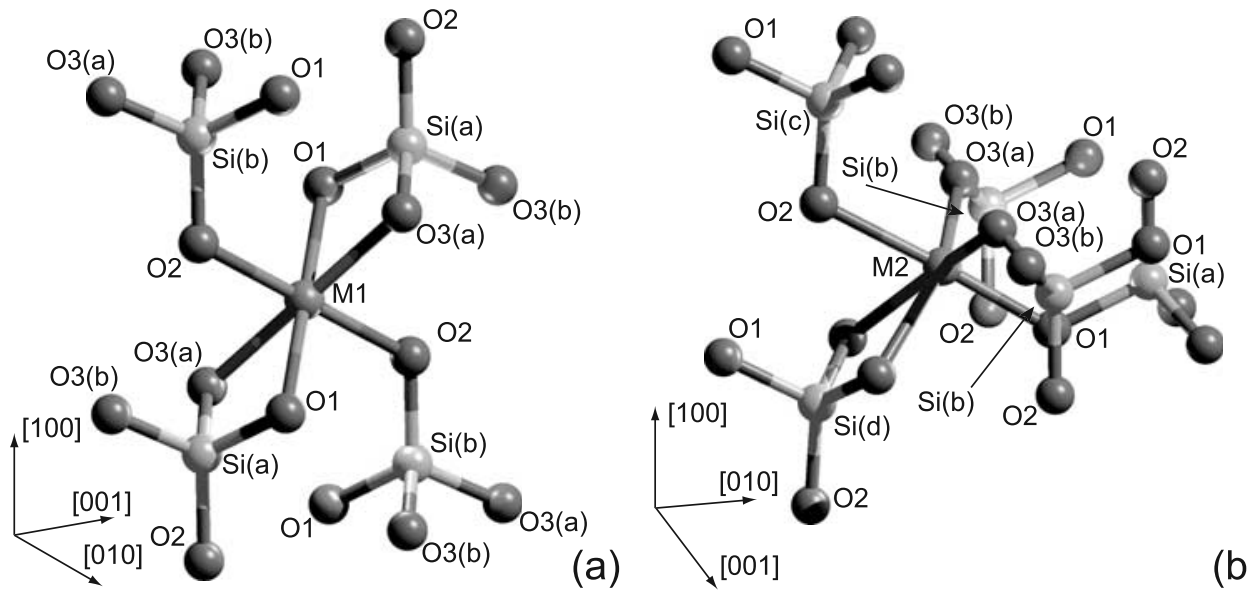

Figure 4. Structure of the two magnesium sites and surrounding silicon tetrahedra in forsterite. (a) M1 site surrounded by two pairs of inequivalent tetrahedra; atom types are marked and letters in parentheses indicate atoms on the same symmetry position that are not equivalent from the point of view of the central M1 site. (b) M2 site surrounded by five tetrahedra. 
tration, while in case (1), the silicon content will covary with titanium content], the preferred mechanism will depend on the chemistry of the crystal's environment. This effect can be assessed by constructing relevant equilibria for the conversion of one defect to the other including the energy to digest or precipitate other oxides. The energies for a range of materials have been calculated, and these are reported along with the lowest energy representative of each type of defective cell in Table 1. In an experiment where titanium-bearing forsterite is in equilibrium with magnesium oxide, the relevant reaction to convert one defect into the other can be written in Kröger-Vink notation as:

$$
\begin{aligned}
& \left\{\mathrm{V}_{\mathrm{M} 1}^{\prime \prime} \mathrm{Ti}_{\mathrm{M} 2 \mathrm{a}}^{\bullet \bullet}\right\}+2 \mathrm{~V}_{\mathrm{Mg}}^{\prime \prime}+\mathrm{V}_{\mathrm{Si}}^{\prime \prime \prime \prime}+4 \mathrm{~V}_{\mathrm{O}}^{\bullet \bullet}+4 \mathrm{MgO} \\
& \quad \rightarrow \mathrm{Ti}_{\mathrm{Si}}^{\times}+4 \mathrm{Mg}_{\mathrm{Mg}}^{\times}+4 \mathrm{O}_{\mathrm{O}}^{\times},
\end{aligned}
$$

or as a reaction between chemical components:

$$
\begin{gathered}
\underset{\mathrm{MgO}}{\text { periclase }}+\mathrm{Ti}^{[6]} \mathrm{SiO}_{4} \cdot 15 \mathrm{Mg}_{2} \mathrm{SiO}_{4} \rightarrow \\
\text { olivine } \\
\mathrm{Mg}_{2} \mathrm{SiO}_{4}+\mathrm{Mg}_{2} \mathrm{Ti}^{[4]} \mathrm{O}_{4} \cdot 15 \mathrm{Mg}_{2} \mathrm{SiO}_{4}
\end{gathered}
$$

which gives an energy of $-169 \mathrm{~kJ} \mathrm{~mol}^{-1}$, strongly favoring the direct substitution of titanium for silicon represented on the right-hand side of this reaction. When there is no magnesium oxide to react and the titanium-bearing forsterite is in equilibrium with orthopyroxene, which is the situation expected in the mantle, the reaction becomes:

$$
\begin{aligned}
& \left\{\mathrm{V}_{\mathrm{M} 1}^{\prime \prime} \mathrm{Ti}_{\mathrm{M} 2 \mathrm{a}}^{\bullet \bullet}\right\}+4 \mathrm{Mg}_{\mathrm{Mg}}^{\times}+4 \mathrm{Si}_{\mathrm{Si}}^{\times}+12 \mathrm{O}_{\mathrm{O}}^{\times} \\
& \quad \rightarrow \mathrm{Ti}_{\mathrm{Si}}^{\times}+6 \mathrm{~V}_{\mathrm{Mg}}^{\prime \prime}+3 \mathrm{~V}_{\mathrm{Si}}^{\prime \prime \prime \prime}+12 \mathrm{~V}_{\mathrm{O}}^{\bullet \bullet}+4 \mathrm{MgSiO}_{3},
\end{aligned}
$$

in Kröger-Vink notation or:

$$
\begin{aligned}
& \mathrm{Ti}^{[6]} \mathrm{SiO}_{4} \cdot 15 \mathrm{Mg}_{2} \mathrm{SiO}_{4}+\underset{\text { olivine }}{3 \mathrm{Mg}_{2} \mathrm{SiO}_{4}} \rightarrow \\
& \mathrm{Mg}_{2} \mathrm{Ti}^{[4]} \mathrm{O}_{4} \cdot 15 \mathrm{Mg}_{2} \mathrm{SiO}_{4}+4 \mathrm{MgSiO}_{3} \\
& \text { olivine enstatite }
\end{aligned}
$$

in terms of a reaction between components. This reaction gives an energy of $-4 \mathrm{~kJ} \mathrm{~mol}^{-1}$, weakly favoring the direct substitution of silicon for titanium, although both substitution mechanisms are likely to be present. It is interesting to note that titanium-bearing forsterite is predicted to be more stable in equilibrium with $\mathrm{MgO}$ compared to enstatite. This prediction is supported by the experimental study of Hermann et al. [2005], who found that titanium concentrations in olivine equilibrated with enstatite (low $\mathrm{MgO}$ activity) were four times lower than in experiments with olivine in equilibrium with spinel structured $\mathrm{Mg}_{2} \mathrm{TiO}_{4}$ (high $\mathrm{MgO}$ activity). Figure 5 shows the results of these experiments which indicate a dependence of $\mathrm{Ti}$ concentration on $\mathrm{MgO}$ activity. For substitution at $12 \mathrm{GPa}$, a pressure close to the forsterite-wadsleyite transition, we have only recalculated the energy of the lowest energy simulation cell for each mechanism found at $0 \mathrm{GPa}$ (Table 1). Using these results, we find that the direct substitution for silicon is destabilized by pressure, and at $12 \mathrm{GPa}$, the enthalpy change associated with reaction (13) is positive with a calculated energy of $55 \mathrm{~kJ} \mathrm{~mol}^{-1}$.

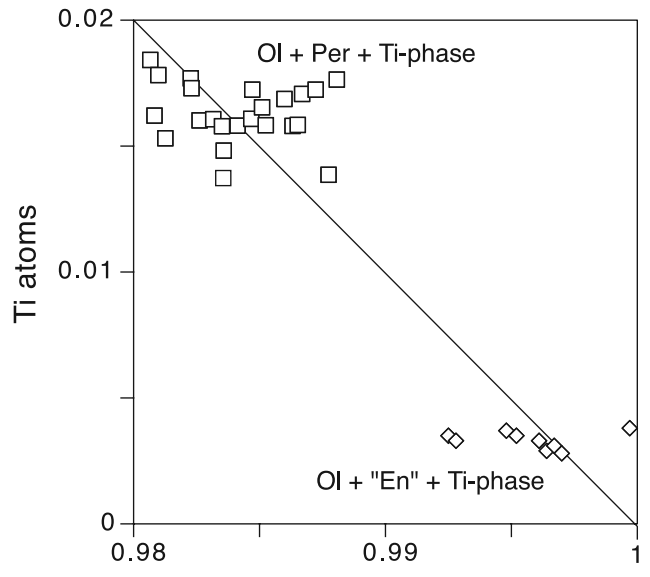

Si atoms

Figure 5. Composition of experimental titanium bearing olivine samples $(\mathrm{Ol}=$ olivine, $\mathrm{Per}=$ periclase, $\mathrm{En}=$ enstatite) equilibrated at $1400^{\circ} \mathrm{C}$ and $1 \mathrm{~atm}$. The line indicates the expected relationship if incorporation occurs by the replacement of silicon with titanium.

\subsection{The "Titanium Clinohumite" Point Defect}

[20] With the knowledge that hydrogen is likely to be incorporated as a doubly protonated magnesium vacancy at mantle temperatures and orthopyroxene-buffering in titanium -free forsterite, and that titanium is likely to be incorporated via the direct substitution for silicon in dry forsterite, we are now in a position to examine the coupled incorporation of titanium and hydrogen proposed by Berry et al. [2005]. Three kinds of substitutional mechanism are conceptually possible. The titanium and hydrogen point defects could be randomly distributed through the crystal, which would maximize the configurational entropy. The defects could be bound but with titanium still occupying the silicon site and the hydrogen ions occupying an adjacent magnesium vacancy. In the third possibility, the defects react: the titanium ion moving from the silicon site into the vacant magnesium site and the two hydrogen ions moving from the magnesium site into the now vacant silicon site. To test to see if the second possibility is likely, we evaluate the energy of the reaction:

$$
(2 \mathrm{H})_{\mathrm{Mg}}^{\times}+\mathrm{Ti}_{\mathrm{Si}}^{\times} \rightarrow\left\{(2 \mathrm{H})_{\mathrm{Mg}}^{\times} \mathrm{Ti}_{\mathrm{Si}}^{\times}\right\},
$$

in Kröger-Vink notation or:

$$
\begin{aligned}
& \begin{array}{l}
\mathrm{MgH}_{2} \mathrm{SiO}_{4} \cdot 15 \mathrm{Mg}_{2} \mathrm{SiO}_{4}+ \\
\text { olivine }
\end{array} \\
& \mathrm{Mg}_{2} \mathrm{Ti}^{[4]} \mathrm{O}_{4} \cdot 15 \mathrm{Mg}_{2} \mathrm{SiO}_{4} \rightarrow \\
& \text { olivine } \\
& \mathrm{MgH}_{2} \mathrm{Ti}^{[4]} \mathrm{O}_{4} \cdot 15 \mathrm{Mg}_{2} \mathrm{SiO}_{4}+\underset{\text { olivine }}{16 \mathrm{Mg}_{2} \mathrm{SiO}_{4},} \\
& \text { olivine }
\end{aligned}
$$

in terms of a reaction between components, giving an energy of $-15 \mathrm{~kJ} \mathrm{~mol}^{-1}$ indicating that the defects are likely to be weakly bound.

[21] The third possibility is evaluated via the reaction:

$$
(2 \mathrm{H})_{\mathrm{Mg}}^{\times}+\mathrm{Ti}_{\mathrm{Si}}^{\times} \rightarrow\left\{\mathrm{Ti}_{\mathrm{Mg}}^{\bullet \bullet}(2 \mathrm{H})_{\mathrm{Si}}^{\prime \prime}\right\}
$$



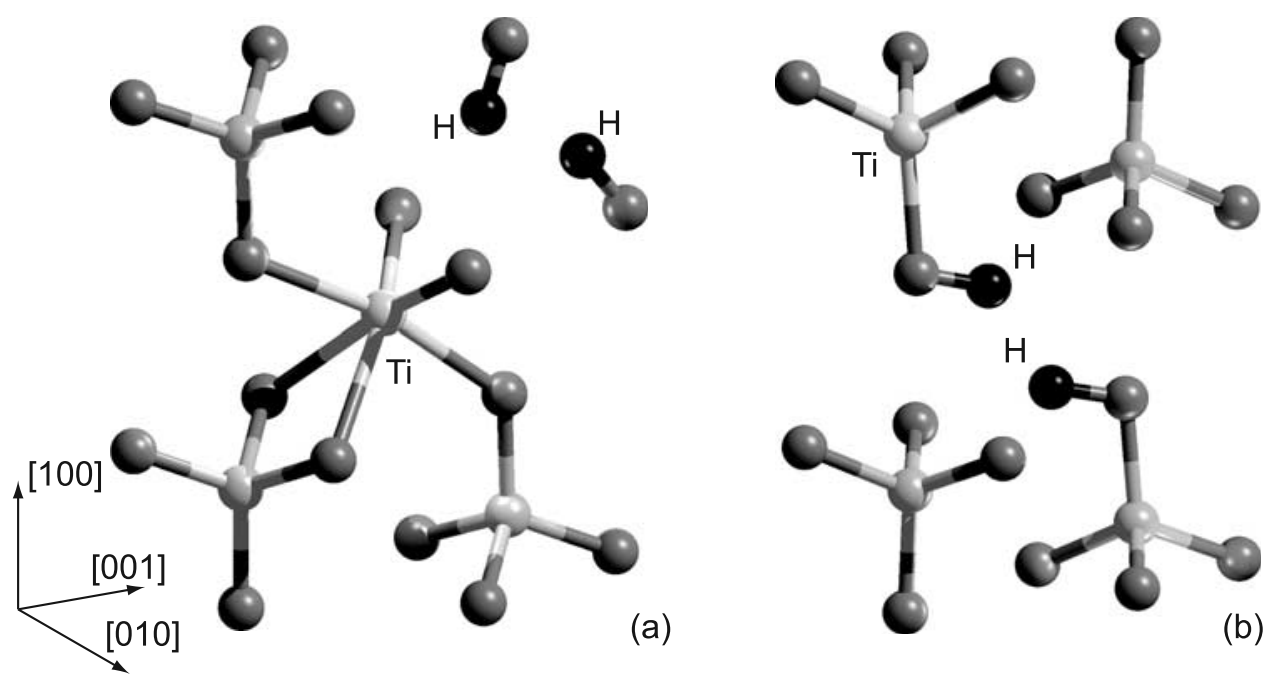

Figure 6. Structure of hydrated titanium defect. (a) Stable defect with titanium on the M1 site next to a silicon vacancy containing two hydrogen atoms; both $\mathrm{OH}$ dipoles have strong resolved components in the [100] direction and smaller components in the [001] direction. (b) Less stable defect with titanium on the silicon site next to a hydrated M1 vacancy similar to that shown in Figure 2b; note the lengthening of the Ti-O bonds compared to the Si-O bonds. Atom types are given in Figure 4; hydrogen atoms are black and titanium atoms are marked.

in Kröger-Vink notation or in terms of a reaction between components:

$$
\begin{aligned}
& \mathrm{MgH}_{2} \mathrm{SiO}_{4} \cdot 15 \mathrm{Mg}_{2} \mathrm{SiO}_{4}+ \\
& \text { olivine } \\
& \mathrm{Mg}_{2} \mathrm{Ti}^{[4]} \mathrm{O}_{4} \cdot 15 \mathrm{Mg}_{2} \mathrm{SiO}_{4} \rightarrow \\
& \text { olivine } \\
& \mathrm{MgTi}^{\mathrm{Mg}_{2} \mathrm{O}_{4} \cdot 15 \mathrm{Mg}_{2} \mathrm{SiO}_{4}}+\underset{\substack{16 \mathrm{Mg}_{2} \mathrm{SiO}_{4} \\
\text { olivine }}}{\text { olivine }},
\end{aligned}
$$

which gives an energy of $-145 \mathrm{~kJ} \mathrm{~mol}^{-1}$ indicating that the reaction will occur. The fact that reaction (15) lowers the enthalpy more than reaction (14) shows that the exchange reaction [reaction (15)] will be favored over the binding reaction [reaction (14)]. At $12 \mathrm{GPa}$, the components on the right-hand side of reaction (15) are further stabilized, and the reaction enthalpy is found to be $-217 \mathrm{~kJ} \mathrm{~mol}^{-1}$. Assuming that the effect of pressure is constant, this gives a volume of this reaction as $-6 \times 10^{-6} \mathrm{~m}^{-3} \mathrm{~mol}^{-1}$.

[22] For completeness, we finally consider the possibility of the reaction between hydrogen from a hydrogarnet-type defect and titanium. Unlike reactions (14) and (15), this involves a change in the chemistry of the olivine crystal and thus depends on the buffer. For the system buffered by orthopyroxene, the reaction is:

$$
\begin{aligned}
& (4 \mathrm{H})_{\mathrm{Si}}^{\times}+2 \mathrm{Ti}_{\mathrm{Si}}^{\times}+3 \mathrm{~V}_{\mathrm{Si}}^{\prime \prime \prime \prime}+6 \mathrm{~V}_{\mathrm{Mg}}^{\prime \prime}+12 \mathrm{~V}_{\mathrm{O}}^{\bullet \bullet} \\
& \quad \rightarrow 2\left\{\mathrm{Ti}_{\mathrm{Mg}}^{\bullet}(2 \mathrm{H})_{\mathrm{Si}}^{\prime \prime}\right\}+4 \mathrm{Si}_{\mathrm{Si}}^{\times}+4 \mathrm{Mg}_{\mathrm{Mg}}^{\times}+12 \mathrm{O}_{\mathrm{O}}^{\times},
\end{aligned}
$$

or

$$
\begin{aligned}
& \underset{\text { olivine }}{\mathrm{Mg}_{2} \mathrm{H}_{4} \mathrm{O}_{4} \cdot 15 \mathrm{Mg}_{2} \mathrm{SiO}_{4}}+\underset{\text { enstatite }}{4 \mathrm{MgSiO}_{3}}+ \\
& 2 \mathrm{Mg}_{2} \mathrm{Ti}^{[4]} \mathrm{O}_{4} \cdot 15 \mathrm{Mg}_{2} \mathrm{SiO}_{4} \rightarrow \\
& \text { olivine } \\
& 2 \mathrm{MgTi}^{[6]} \mathrm{H}_{2} \mathrm{O}_{4} \cdot 15 \mathrm{Mg}_{2} \mathrm{SiO}_{4}+19 \mathrm{Mg}_{2} \mathrm{SiO}_{4} \text {, } \\
& \text { olivine olivine }
\end{aligned}
$$

while for an $\mathrm{MgO}$-buffered system, the reaction is:

$$
\begin{aligned}
& (4 \mathrm{H})_{\mathrm{Si}}^{\times}+2 \mathrm{Ti}_{\mathrm{Si}}^{\times}+4 \mathrm{Mg}_{\mathrm{Mg}}^{\times}+4 \mathrm{O}_{\mathrm{O}}^{\times} \rightarrow 2\left\{\mathrm{Ti}_{\mathrm{Mg}}^{\bullet \bullet}(2 \mathrm{H})_{\mathrm{Si}}^{\prime \prime}\right\} \\
& +\mathrm{V}_{\mathrm{Si}}^{\prime \prime \prime \prime}+2 \mathrm{~V}_{\mathrm{Mg}}^{\prime \prime}+4 \mathrm{~V}_{\mathrm{O}}^{\bullet \bullet}+4 \mathrm{MgO},
\end{aligned}
$$

or

$$
\begin{aligned}
& \mathrm{Mg}_{2} \mathrm{H}_{4} \mathrm{O}_{4} \cdot 15 \mathrm{Mg}_{2} \mathrm{SiO}_{4}+ \\
& \text { olivine } \\
& 2 \mathrm{Mg}_{2} \mathrm{Ti}^{[4]} \mathrm{O}_{4} \cdot 15 \mathrm{Mg}_{2} \mathrm{SiO}_{4} \rightarrow \\
& \text { olivine } \\
& \begin{array}{l}
2 \mathrm{MgTi}^{[6]} \mathrm{H}_{2} \mathrm{O}_{4} \cdot 15 \mathrm{Mg}_{2} \mathrm{SiO}_{4}+\underset{1}{15 \mathrm{Mg}_{2} \mathrm{SiO}_{4}}+ \\
\text { olivine } \\
\text { olivine } \\
\text { periclase }
\end{array}
\end{aligned}
$$

The energy of reaction (16) is found to be $-229 \mathrm{~kJ} \mathrm{~mol}^{-1}$ indicating that at mantle conditions, the bound defect is also more stable than the isolated titanium and hydrogarnet defects. Again, the hydrous titanium point defect is stabilized by pressure; at $12 \mathrm{GPa}$, the reaction energy is found to be $-316 \mathrm{~kJ} \mathrm{~mol}^{-1}$. Reaction (17) is also favored with a reaction energy of $-64 \mathrm{~kJ} \mathrm{~mol}^{-1}$ at $12 \mathrm{GPa}$. The contribution to the free energy change associated with reactions (14)-(17) from the change in configurational entropy will favor the unbound titanium and hydrated cation vacancies.

[23] An advantage of the calculations described here is that they provide not only information about the energies of defects but also the complete structure of the defects, including the titanium and hydrogen positions, that lead to these low-energy configurations (for example, Figure 6). Reactions (15)-(17), at all pressures, give the lowest energy configuration consisting of a titanium ion occupying one of the small M1 sites located on an inversion center in the olivine structure. The M1 site is surrounded by two symmetrydistinct pairs of silicon tetrahedra: One pair shares an O1-O3 edge with the M1 octahedron, while the second 
Table 3. Total Energies For All "Titanium-Clinohumite" Defect Containing Simulation Cells in Forsterite ${ }^{a}$

\begin{tabular}{|c|c|}
\hline Defect & Energy, eV \\
\hline 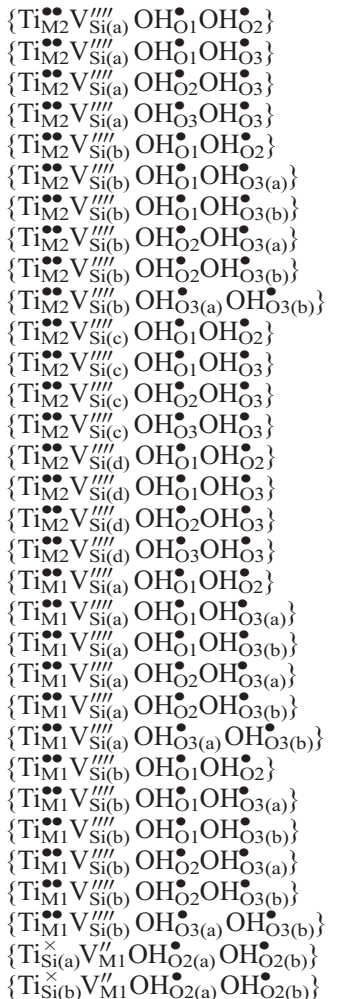 & $\begin{array}{l}-62,973.43 \\
-62,973.42 \\
-62,973.43 \\
-62,973.66 \\
-62,973.29 \\
-62,973.29 \\
-62,973.51 \\
-62,971.26 \\
-62,973.46 \\
-62,973.46 \\
-62,972.82 \\
-62,972.82 \\
-62,973.05 \\
-62,973.05 \\
-62,974.18 \\
-62,973.43 \\
-62,973.42 \\
-62,972.07 \\
-62,973.35 \\
-62,974.63 \\
-62,974.63 \\
-62,973.49 \\
-62,974.63(*) \\
-62,974.63 \\
-62,972.67 \\
-62,972.66 \\
-62,972.68 \\
-62,972.68 \\
-62,972.69 \\
-62,972.89 \\
-62,973.17 \\
-62,973.28(*)\end{array}$ \\
\hline
\end{tabular}

${ }^{a}$ The structure of the cells marked with an asterisk are shown in Figure 6.

shares only the $\mathrm{O} 2$ vertex (Figure $4 \mathrm{a}$ ). In the stable configuration, one of the edge sharing tetrahedra is occupied by two hydrogen ions rather than a silicon ion. The hydrogen ions are bonded to the two oxygen atoms that do not form part of the M1 octahedron containing the titanium ion (Figure 6a). In this way, all four oxygen atoms surrounding the vacant silicon site form covalent bonds (with hydrogen or with titanium), and the silicon vacancy is stabilized. Of the 30 symmetry-distinct ways of arranging the ions in the titaniumclinohumite point defect (where Ti occupies a Mg site; see Figure 4 and Table 3), only two have all four oxygen ions around the silicon vacancy bonded to either titanium or hydrogen. The second arrangement has the titanium atom occupying an M2 site and the hydrogen ions bonded to $\mathrm{O} 1$ and $\mathrm{O} 2$ oxygen atoms (the two $\mathrm{O} 3$ atoms bond to the titanium). This arrangement is $0.45 \mathrm{eV}$ less stable than the first arrangement with titanium on M1; while the driving force for this stabilization cannot be determined directly from the calculations performed here, it is likely that the known preference for hydrogen to bond to $\mathrm{O} 2$ and $\mathrm{O} 3$ (rather than O1) atoms [Wright and Catlow, 1994; Brodholt and Refson, 2000; Braithwaite et al., 2003; Walker et al., 2006] plays a role. Other arrangements with at least one underbonded oxygen atom are at least $0.5 \mathrm{eV}$ (and typically more than $1 \mathrm{eV}$ ) less stable than the two fully bonded cases.

\section{Discussion}

[24] The results of the calculations presented above show that if water is incorporated into titanium-bearing forsterite, composite defects will form that consist of a titanium ion occupying an M1 site adjacent to a silicon vacancy. Two of the four oxygen ions surrounding the vacancy form covalent bonds with the titanium atom, and the remaining two bond with hydrogen to form hydroxyl groups, thereby stabilizing all four underbonded oxygen ions around the silicon vacancy. The existence of this configuration is supported by the results of IR and X-ray absorption near edge structure (XANES) spectroscopy [Berry et al., 2005; Berry et al., 2007]. The effect of this defect is to introduce silicon vacancies into the forsterite structure, which is expected to decrease its strength significantly.

\subsection{Comparison With Experiment}

[25] The first evidence that our predicted structures are correct is provided by a comparison of the orientation of the $\mathrm{O}-\mathrm{H}$ bonds from the calculations and the directions of maximum absorbance of IR radiation in experiments where the sample is orientated and the light is polarized. The IR spectra of the experimental samples of Lemaire et al. [2004] provide constraints on the hydrated cation vacancies formed in titanium-free conditions. Their interpretation is that the IR bands between 3550 and $3650 \mathrm{~cm}^{-1}$ are related to a silicon vacancy bound to hydroxyl groups, and the measured absorbance is strongest when the electric vector is parallel to [100] and [001], compared to [010]. This pattern of polarization would also be predicted from the calculated structure shown in Figure 2a, which has three of the four O-H bonds aligned nearly parallel to [100] and the fourth nearly parallel to [001]. The interpretation of Lemaire et al. [2004] of the IR band close to $3160 \mathrm{~cm}^{-1}$, which is only observed in samples of high silica activity and when the electric vector is parallel to [001], is that this band is related to hydroxyl associated with magnesium vacancies in their sample. The calculated structure of this defect (Figure $2 b$ ) suggests that the polarization direction should be in [001], in agreement with the experimental observation. We note that the structure of the two defects has also been calculated by Braithwaite et al. [2003] and Brodholt and Refson [2000] using independent methods, both of which were different to the computational methodology used in this study. The structure of the magnesium vacancy-hydroxyl cluster is the same in all three cases, but the details of the structure of the hydrogen-silicon vacancy clusters are different. Braithwaite et al. [2003] give polarization directions due to $\mathrm{O}-\mathrm{H}$ bonds around the silicon vacancy as being parallel to [100] and [010], and while Brodholt and Refson [2000] do not explicitly state the direction of the O-H bonds, it is clear from their Figure 3 that an [010] component would be expected. Polarized IR spectra from the experimental titanium-bearing samples of Berry et al. [2005] are not available because of the small sample size. However, we measured polarized IR spectra along the main axes of a San Carlos olivine cube (Figure 1). This olivine displays the typical Ti-OH fingerprint identified by Berry et al. [2005]. The polarized spectra show the strongest absorption when the electric vector is parallel to the [100] direction, about a factor of 10 less absorption when the vector is parallel to [001], and essentially no absorption when the vector is parallel to [010] (Figure 1). This is exactly the polarization behavior that would be expected for the most stable defect containing both hydrogen and 
titanium shown in Figure 6a, which has $\mathrm{O}-\mathrm{H}$ bonds in the (010) plane. It is important to note that Ti-free olivine that has four $\mathrm{OH}^{-}$groups surrounding silicon vacancies (Figure 2a) displays a very similar polarization behavior, and thus the two Si-defect types cannot be distinguished using this approach. However, the comparison between the calculated positions of the $\mathrm{O}-\mathrm{H}$ bonds with polarized infrared spectroscopy provides strong evidence that $\mathrm{H}$ decorating a $\mathrm{Si}$ or a $\mathrm{Mg}$ vacancy can be distinguished. This approach confirms earlier suggestions that IR bands in the region of $3612-3525 \mathrm{~cm}^{-1}$ are related to $\mathrm{Si}$ vacancies, and the broad peaks at $3220-3160 \mathrm{~cm}^{-1}$ are related to $\mathrm{Mg}$ vacancies [Lemaire et al., 2004; Berry et al., 2005].

[26] Additional experimental constraints also support the results of the simulations presented above. Most obviously, the IR spectrum of the hydrated titanium defect is similar to the IR spectrum for forsterite equilibrated with $\mathrm{MgO}$ (see Figure 1). If the assumption that the high wave number $\mathrm{MgO}$ equilibrated fingerprint corresponds to a hydrated silicon vacancy is correct, an assumption that is strongly supported by the calculated IR frequencies of Braithwaite et al. [2003], then the similarity between the two fingerprints reflects the similar structure found in the two defects. Further supporting results relate to the mechanism of titanium incorporation in hydrogen-free forsterite. The incorporation mechanism has been examined by Hermann et al. [2005] who found that the titanium concentration in hydrogen-free olivine equilibrated in the presence of rutile covaries with the concentration of silicon in the sample, while the concentration of magnesium is independent of the titanium content (Figure 5). This supports the view that titanium incorporation should occur via substitution of titanium for silicon as proposed above. Extended X-ray absorption fine structure (EXAFS) spectroscopy is also consistent with this model, with experimentally determined Ti-O bond lengths being in good agreement with the structure derived from calculation. The calculated bond lengths for titanium on the magnesium sites are significantly too long to reconcile with the EXAFS results [Berry et al., $2007]$.

[27] The XANES results reported by Berry et al. [2005] are also in agreement with the calculated structure of the defects. These experiments use the energy and intensity of the $1 \mathrm{~s} \rightarrow 3 \mathrm{~d}$ pre-edge peak in the K-edge absorption spectrum to determine the coordination number of titanium from an empirical correlation. In particular, the XANES spectrum of hydrogen-free olivine shows the presence of tetrahedrally coordinated titanium, while the spectrum of hydrated titanium-bearing olivine shows the presence of octahedrally coordinated titanium. Thus XANES experiments strongly support the conclusion that a mechanism like reaction (15) is energetically favored.

\subsection{Diffusion and Water Weakening}

[28] The results of the calculations provide an atomicscale view of the naturally occurring hydrogen defects in olivine, which permits conclusions about the effect of hydrogen on, for example, electrical conductivity and cation mobility to be assessed. Of crucial importance for the physical properties of olivine is the presence of a silicon vacancy in the proposed titanium-clinohumite point-defect cluster. However, the situation is complicated as there is no completely accepted model that relates the diffusivity of the constituents of a chemically complex ionic material to its creep rate. The standard model, in which diffusion of the most slowly moving species moving by the most rapid pathway limits creep [Poirier, 1985], works well in binary oxides deforming by bulk diffusion and grain boundary sliding, or by dislocation climb, but is less successful in the case of olivine. For example, typical activation energies for anhydrous polycrystalline olivine deforming by a dislocation climb-limited process are $\sim 510 \mathrm{~kJ} \mathrm{~mol}^{-1}$ [e.g., Mei and Kohlstedt, 2000b] with activation volumes that vary between $6 \times 10^{-6}$ and $27 \times 10^{-6} \mathrm{~m}^{3} \mathrm{~mol}^{-1}$ (see the review of Hirth and Kohlstedt [2003]). The fact that silicon is the most slowly diffusing species in olivine was established by Houlier et al. [1988], and there are experimental studies that report activation energies and volumes. Houlier et al. [1990] found a much lower activation energy for silicon diffusion $\left(291 \mathrm{~kJ} \mathrm{~mol}^{-1}\right)$ than the activation energy for creep. Later experiments to extract the activation volume for silicon diffusion gave results close to $0 \mathrm{~m}^{3} \mathrm{~mol}^{-1}$ [Béjina et al., 1997, 1999], also significantly different from the observed pressure effect for creep. An attempt to rigorously explain these differences was made by Jaoul [1990] who could reconcile them by requiring that the driving force for diffusion consisted of a gradient in the chemical potential and electrostatic interactions between diffusing defects. However, later experiments recovered an activation energy for silicon diffusion of $529 \pm 41 \mathrm{~kJ} \mathrm{~mol}^{-1}$ (within error of the activation energy for creep [Dohmen et al., 2002]). It is unclear if new experiments at high pressure would result in a change in the activation volume for diffusion and invalidate the model of Jaoul [1990], but whatever the correct model for the deformation of olivine is, it seems most likely that silicon diffusion will play a major role. With this in mind, the most probable model for water weakening in forsterite is for water incorporation to increase the number of silicon vacancies in the crystal.

[29] The critical importance of silicon vacancies in relation to the water weakening mechanism was recognized by Brodholt and Refson [2000], who showed that hydrogen acts to lower the formation energy of silicon and magnesium vacancies. At any temperature, this would lead to more intrinsic defects than would be present in a hydrogen-free crystal, leading to a water weakening effect. However, at most temperatures, the expectation is that the defect population in natural olivine will be dominated by extrinsic defects formed by the incorporation of impurities. For the titanium-free system, adding water is likely to increase the number of magnesium vacancies and not directly alter the number of silicon vacancies. In the titanium-bearing system, the addition of water directly increases the concentration of silicon vacancies: for each absorbed molecule of water, there will be one additional silicon vacancy as long as there is sufficient titanium to act as an agent for its stabilization. The diffusivity of silicon is therefore expected to be directly proportional to the amount of incorporated water allowing very significant water weakening.

[30] A related problem is the effect of the proposed titanium-hydrogen point defect on the atomic-scale diffusion mechanism of silicon in olivine. If the mechanism for the diffusion of silicon vacancies or interstitial ions in pure 
forsterite is significantly different from the mechanism for diffusion of the silicon vacancy in the hydrated point defect described here, it is likely that the energetic barrier to pointdefect migration and thus the activation energy for diffusion will be different in the two cases. Although the evaluation of the activation energy for diffusion from atomic-scale simulation is possible [Walker et al., 2003; Jaoul et al., 1995], the computational resources required are significantly in excess of those needed for identifying the structure and energies of stable and metastable point defects, and we have not attempted such calculations for the proposed defect. However, it seems probable that any diffusion pathway would involve some of the metastable configurations for the titanium-hydrogen point defect identified in Table 3. If this is the case, it is possible to place a lower bound on the activation energy for diffusion equal to the difference in energy between the lowest-energy stable configuration and higher-energy metastable configurations. Depending on which defect configurations are chosen as the metastable state, this limit is between 50 and $150 \mathrm{~kJ} \mathrm{~mol}^{-1}$, significantly less than the energy required to form an intrinsic silicon vacancy [Braithwaite et al., 2003]. This may partially explain the influence of water on silicon diffusion recently reported by Chakraborty and Costa [2004].

\section{Conclusions}

[31] The calculations indicate the following: (1) at low pressure, the most stable configuration for titanium in anhydrous forsterite is a direct substitution for silicon; this is supported by XANES and EXAFS data; (2) the most stable configuration for cations and hydrogen in titaniumfree forsterite coexisting with pyroxene is the formation of hydrated magnesium vacancies on the smaller of the two magnesium sites; (3) the reaction of titanium and the hydrated cation vacancy is thermodynamically favored and results in the formation of a cluster of point defects with six-coordinated titanium on a magnesium site adjacent to a vacant silicon site containing two hydrogen ions. As silicon is the most slowly diffusing species in olivine, increasing the number of silicon vacancies is expected to lead to a weakening of olivine in the dislocation climb and diffusion creep deformational regimes. The process outlined above will lead to an increase in the number of silicon vacancies in olivine as hydrogen is incorporated into the crystal and thus amounts to a novel and credible explanation for the observed water weakening of olivine. Furthermore, the results of the computer calculations are in agreement with a wide range of experimental observations. As well as the results of X-ray and IR spectroscopy outlined above, the mechanism is consistent with the dependence of water solubility on oxygen partial pressure found for "group I" bands by Bai and Kohlstedt [1993]. These bands were found to vary with the $\sim 1 / 6$ power of the oxygen partial pressure, and according to the point-defect models of Stocker and Smyth [1977], this indicates that hydrogen incorporation is either charge balanced by magnesium vacancies or oxygen interstitials. Because reactions such as reaction (15) do not change the stoichiometry of the crystal (they only rearrange the position of the defects), the dependence of hydrogen solubility with oxygen partial pressure is unaffected by the action of our proposed incorporation mechanism; the dependence is not changed by the presence of titanium.

[32] Finally, we note that our results are expected to hold for all upper mantle pressures. However, samples synthesized at pressures greater than $5 \mathrm{GPa}$ show IR bands that are not explained by the Ti-mechanism suggested here [Kohlstedt et al., 1996] and correspond to the signature of hydrated silicon vacancies identified by Matveev et al. [2001], Lemaire et al. [2004], and Berry et al. [2005]. Indeed, Berry et al. [2005] suggest that while water is incorporated at the hydrated Ti point defect in olivine from spinel peridotite, the hydrated silicon vacancy becomes more important with increasing pressure. Although we do not predict a major pressure-induced change in the relative stability of the hydrated silicon vacancy compared to either the hydrated magnesium vacancy [reactions (3) and (4)] or the hydrated titanium point defect [reactions (16) and (17)] with pressure, this does not rule out the possibility of an increase in the stability of this defect as the pressure and temperature conditions approach the stability field of a hydrous phase (such as $\mathrm{OH}$-clinohumite). Such an increase in stability could alter the relative stability of any of the classes of defects examined here at very high pressure. Alternatively, at higher $f_{\mathrm{H}_{2} \mathrm{O}}$ and greater $\mathrm{H}_{2} \mathrm{O}$ solubilities, the hydrated silicon vacancy could be stabilized by the entropic effects discussed in section 3.1, even when the olivine is buffered by $\mathrm{MgSiO}_{3}$.

[33] Acknowledgments. We thank the Australian Partnership for Advanced Computing and the Centre for Advanced Data Inference for access to high-performance computer facilities. J.H. and A.J.B. acknowledge financial support from the Australian Research Council.

\section{References}

Bai, Q., and D. L. Kohlstedt (1993), Effects of chemical environment on the solubility and incorporation mechanism for hydrogen in olivine, Phys. Chem. Miner., 19, 460-471.

Béjina, F., P. Raterron, J. Zhang, O. Jaoul, and R. C. Liebermann (1997), Activation volume of silicon diffusion in San Carlos olivine, Geophys. Res. Lett., 24, 2597-2600.

Béjina, F., O. Jaoul, and R. C. Liebermann (1999), Activation volume of Si diffusion in San Carlos olivine: Implications for upper mantle rheology, J. Geophys. Res., 104, 25,529-25,542.

Berry, A. J., J. Hermann, H. St. C. O'Neill, and G. J. Foran (2005), Fingerprinting the water site in mantle olivine, Geology, 33, 869-872.

Berry, A. J., A. M. Walker, J. Hermann, H. St. C. O’Neill, G. J. Foran, and J. D. Gale (2007), Titanium substitution mechanisms in forsterite, Chem. Geol., doi:10.1016/j.chemgeo.2007.03.010, in press.

Braithwaite, J. S., K. Wright, and C. R. A. Catlow (2003), A theoretical study of the energetics and IR frequencies of hydroxyl defects in forsterite, J. Geophys. Res., 108(B6), 2284, doi:10.1029/2002JB002126.

Brodholt, J. P., and K. Refson (2000), An ab initio study of hydrogen in forsterite and a possible mechanism for hydrolytic weakening, J. Geophys. Res., 105, 18,977-18,982.

Chakraborty, S., and F. Costa (2004), Fast diffusion of Si and O in San Carlos olivine under hydros conditions, Geochim. Cosmochim. Acta, 68, A275.

Dohmen, R., S. Chakraborty, and H.-W. Becker (2002), Si and O diffusion in olivine and implications for characterizing plastic flow in the mantle, Geophys. Res. Lett., 29(21), 2030, doi:10.1029/2002GL015480.

Evans, R. L., et al. (1999), Asymmetric electrical structure in the mantle beneath the East Pacific Rise at $17^{\circ} \mathrm{S}$, Science, 289, 752-756.

Gatzemeier, A., and M. Moorkamp (2005), 3D modelling of electrical anisotropy from electromagnetic array data: Hypothesis testing for different upper mantle conduction mechanisms, Phys. Earth Planet. Inter, 149, 225-242.

Hermann, J., H. S. O’Neill, and A. J. Berry (2005), Titanium solubility in olivine in the system $\mathrm{TiO}_{2}-\mathrm{MgO}-\mathrm{SiO}_{2}$ : No evidence for an ultra-deep origin of Ti-bearing olivine, Contrib. Mineral. Petrol., 148, 746-760. 
Hirth, G., and D. Kohlstedt (2003), Rheology of the upper mantle and the mantle wedge: A view from the experimentalists, in Microscopic Properties and Processes in Minerals, Geophysical Monograph Series, vol. 138, edited by J. Eiler, pp. 83-105, AGU, Washington, D. C.

Hohenberg, P., and W. Kohn (1964), Inhomogeneous electron gas, Phys. Rev., 136, 864-871.

Houlier, B., O. Jaoul, F. Abel, and R. C. Liebermann (1988), Oxygen and silicon self-diffusion in natural olivine, Phys. Earth Planet. Inter., 50, $240-250$.

Houlier, B., M. Cheraghmakani, and O. Jaoul (1990), Silicon diffusion in San Carlos olivine, Phys. Earth Planet. Inter., 62, 329-340.

Jaoul, O. (1990), Multicomponent diffusion and creep in olivine, J. Geophys. Res., 95, 17,631-17,642.

Jaoul, O., Y. Bertran-Alvarez, R. C. Liebermann, and G. D. Price (1995), Fe-Mg interdiffusion in olivine up to $9 \mathrm{GPa}$ at $\mathrm{T}=600-900^{\circ} \mathrm{C}$; experimental data and comparison with defect calculations, Phys. Earth Planet. Inter., 89, 199-218.

Junquera, J., O. Paz, D. Sánchez-Portal, and E. Artacho (2001), Numerical atomic orbitals for linear-scaling calculations, Phys. Rev. B, 64(235), 111.

Karato, S.-I. (1990), The role of hydrogen in the electrical conductivity of the upper mantle, Nature, 347, 272-273.

Karato, S.-I., and H. Jung (1998), Water, partial melting and the origin of the seismic low velocity and high attenuation zone in the upper mantle, Earth Planet. Sci. Lett., 157, 193-207.

Kaula, W. M. (1990), Venus: A contrast in evolution to Earth, Science, 247, $1191-1196$.

Kaula, W. M. (1995), Venus reconsidered, Science, 270, 1460-1464.

Koch-Müller, M., S. S. Matsyuk, D. Rhede, R. Wirth, and N. Khisina (2006), Hydroxyl in mantle olivine xenocrysts from the Udachnaya kimberlite pipe, Phys. Chem. Miner., 33, 276-287.

Kohlstedt, D. L., H. Keppler, and D. C. Rubie (1996), Solubility of water in the alpha, beta and gamma phases of $(\mathrm{MgFe})_{2} \mathrm{SiO}_{4}$, Contrib. Mineral. Petrol., 123, 345-357.

Kohn, W., and L. J. Sham (1965), Self-consistent equations including exchange and correlation effects, Phys. Rev., 140, 1133-1138.

Lemaire, C., S. C. Kohn, and R. A. Brooker (2004), The effect of silica activity on the incorporation mechanisms of water in synthetic forsterite: A polarized infrared spectroscopic study, Contrib. Mineral. Petrol., 147 $48-57$.

Lizarralde, D., A. Chave, G. Hirth, and A. Schultz (1995), Northeastern Pacific mantle conductivity profile from long-period magnetotelluric sounding using Hawaii-to-California submarine cable data, J. Geophys. Res., 100, 17,837-17,854.

Martin, R. M. (2004), Electronic Structure Basic Theory and Practical Methods, Cambridge Univ. Press, New York.

Matsyuk, S. S., and K. Langer (2004), Hydroxyl in olivines from mantle xenoliths in kimberlites of the Siberian platform, Contrib. Mineral. Petrol., 147, 413-437.

Matveev, S., H. St. C. O’Neill, C. Ballhaus, W. R. Taylor, and D. H. Green (2001), Effect of silica activity on OH-IR spectra of olivine: implications for low-aSiO 2 mantle metasomatism, J. Petrol., 42, 721-729.
Matveev, S., M. Potnyagin, C. Ballhaus, R. A. Brooker, and C. A. Geiger (2005), FTIR spectrum of phenocryst olivine as an indicator of silia saturation in magmas, J. Petrol., 46, 605-614.

Mei, S., and D. L. Kohlstedt (2000a), Influence of water on plastic deformation of olivine aggregates, 1. diffusion creep regime, J. Geophys. Res., $105,21,457-21,469$

Mei, S., and D. L. Kohlstedt (2000b), Influence of water on plastic deformation of olivine aggregates, 2. dislocation creep regime, J. Geophys. Res., 105, 21,471-21,481.

Ordejón, P., et al. (2001), Linear scaling DFT calculations with numerical atomic orbitals, Mater. Res. Soc. Symp. Proc., 677, AA9.6.1-AA9.6.12.

Perdew, J. P., K. Burke, and M. Emzerhof (1996), Generalized gradient approximation made simple, Phys. Rev. Lett., 77, 3865-3868.

Poirier, J.-P. (1985), Creep of Crystals. High-Temperature Deformation Processes in Metals, Ceramics and Minerals, Cambridge Earth sciences series, Cambridge Univ. Press, New York.

Regenauer-Lieb, K., and T. Kohl (2003), Water and diffusivity in olivine: Its role in planetary tectonics, Mineral. Mag., 67, 697-715.

Regenauer-Lieb, K., D. A. Yuen, and J. Branlund (2001), The initiation of subduction: Criticality by addition of water?, Science, 294, 578-580.

Richmond, N. C., and J. P. Brodholt (2000), Incorporation of $\mathrm{Fe}^{3+}$ into forsterite and wadsleyite, Am. Mineral., 85, 1155-1158.

Soler, J. M., E. Artacho, J. D. Gale, A. García, J. Junquera, P. Ordejón, and D. Sánchez-Portal (2002), The siesta method for ab initio order-N materials simulation, J. Phys. Condens. Matter, 14, 2745-2776.

Solomon, S. C., J. W. Head, W. M. Kaula, D. McKenzie, B. Parsons, R. J. Phillips, G. Schubert, and M. Talwani (1991), Venus tectonics initial analysis from Magellan, Science, 252, 297-321.

Stocker, R. L., and D. M. Smyth (1977), Effect of enstatite activity and oxygen partial pressure on the point-defect chemistry of olivine, Phys. Earth Planet. Inter., 16, 145-156.

Walker, A. M., K. Wright, and B. Slater (2003), A computational study of oxygen diffusion in olivine, Phys. Chem. Miner, 30, 536-545.

Walker, A. M., S. Demouchy, and K. Wright (2006), Computer modelling of the energies and vibrational properties of hydroxyl groups in $\alpha$ - and $\beta$ $\mathrm{Mg}_{2} \mathrm{SiO}_{4}$, Eur. J. Mineral., 18, 529-543.

Wang, D., M. Mookherjee, Y. Xu, and S. I. Karato (2006), The effect of water on the electrical conductivity of olivine, Nature, 443, 977-980.

Wright, K., and C. R. A. Catlow (1994), A computer simulation study of $(\mathrm{OH})$ defects in olivine, Phys. Chem. Miner., 20, 515-518.

Yoshino, T., T. Matsuzaki, S. Yamashita, and T. Katsura (2006), Hydrous olivine unable to account for conductivity anomaly at the top of the asthenosphere, Nature, 443, 973-976.

A. J. Berry, Department of Earth Science and Engineering, Imperial College London, South Kensington, London, SW7 2AZ, UK.

J. Hermann and H. St. C. O’Neill, Research School of Earth Sciences, The Australian National University, Mills Road, Canberra, ACT 0200, Australia.

A. M. Walker, Department of Earth Sciences, University of Cambridge, Downing Street, Cambridge, CB2 3EQ, UK. (amw75@cam.ac.uk) 